\title{
The Design of Fuzzy-Based Weaning Protocol in LabVIEW Environment
}

[Hasan Guler]

\begin{abstract}
The main purpose of this study is to design universally accepted approach to weaning patients from ventilator. Fuzzy logic controller was used for achieving this aim. The reason for the use of fuzzy controller is that it represents expert notions employed in decision making. The developed all protocols were designed on LabVIEW software. The inputs of the developed system were $\mathrm{PH}$, partial carbondioxide percent $\left(\mathrm{PaCO}_{2}\right)$, saturation of oxygen $\left(\mathrm{SpO}_{2}\right)$, the rate of $\mathrm{PaO}_{2} / \mathrm{FiO}_{2}$, saturation of oxygen $\left(\mathrm{SaO}_{2}\right)$, hemoglobin $(\mathrm{Hb})$ and positive end expiratory pressure (PEEP). 20 clinical scenarios were generated by using Monte-Carlo simulations and Gaussian distribution method to test performance of the developed protocol. The generated scenarios were applied to the developed protocol. Clinician was asked to evaluate the each scenario to determine weaning probability. Student $t$-test for $\mathbf{p}<0.05$ was used to show statistical difference between the developed protocol and clinician's evaluation. According to results, there is no statistical difference for $\% 97.8$ probability between them
\end{abstract}

Keywords-Weaning, fuzzy system, student t-test, Gaussion Distribution

\section{Introduction}

Weaning patients from mechanical ventilator is important process. It was reported that twenty percentages of the ventilated patients fail their first attempt at weaning [1-3]. Hence, the patients spend more time in intensive care units (ICU) to wean from MV. Prolonged MV may cause some complications such as infection, pneumonia, barotraumas [4$6]$. However, if the clinicians cannot predict the right time to start weaning, the patients may need the reintubation and so, this failure may increase the percentage of morbidity and mortality [7-9]. Many researchers have attempted to reduce the duration of MV and have declared reducing the weaning times by their defined protocols rather than usual intensive care protocols [10-12].

\section{Hasan GULER}

line 1 Firat University

line 2: Turkey

Line 3: Department of Electrical-Electronics Engineering,

Faculty of Engineering

Ugur KILIC

line 1 Harran University

line 2: Turkey

Line 3: Department of Electrical-Electronics Engineering,

Faculty of Engineering

Turgay KAYA

line 1 Firat University

line 2: Turkey

Line 3: Department of Electrical-Electronics Engineering,

Faculty of Engineering
In literature, many studies about weaning from ventilator have been done according to the three weaning predictor such as rapid shallow breathing index (RSBI), pressure time index (PTI) and Jabour' weaning index (JWI) [13-15]. Owing to its ease of calculation, RSBI is widely used in ICU.

According to one minute spontaneous breathing of patient, RSBI calculates the ratio of frequency to tidal volume. If this value is below the threshold of 100 (breaths/min)/L, RSBI predicts weaning success with a sensitivity of up to 97 $\%$ [16]. However, prolonged MV decreases sensitivity of RSBI and the state of disease influences the specificity of that [17-19]. The other predictors used in weaning process require more detailed respiratory parameters and so they cannot be preferred by staff of ICU. Thus, there is no broadly accepted protocol to weaning patients from mechanical ventilator.

In this study, it was attempted to constitute a new LabVIEW-fuzzy based weaning protocol. The aim of the study is to eliminate disadvantages of the predictors used in literature. The weaning system was designed in LabVIEW. The reason of preferring the LabVIEW program is its graphic based structure and the ease provided to user in constituting interface. In addition, fuzzy logic controller can be easily created by using Fuzzy Logic Toolkit on LabVIEW software. Seven vital parameters were used to determine weaning probability. Three of them such as $\mathrm{PH}$, $\mathrm{PaCO}_{2}$ and $\mathrm{SpO}_{2}$ were used to determine acid-base balance and the other parameters such as $\mathrm{PaO}_{2} / \mathrm{FiO}_{2}, \mathrm{SaO}_{2}, \mathrm{Hb}$ and PEEP were used to determine adequate oxygenation. Acidbase balance and adequate oxygenation determined the percentage of weaning probability. First of all, 20 clinical scenarios for seven parameters were generated by using Monte-Carlo simulations and Gaussian distribution. The generated scenarios were applied to the developed protocol. In addition, clinician evaluated the each scenario, independently. Finally, student t-test was used to show statistical difference between the developed protocol and clinician's evaluation. According to the obtained results, there is no statistical difference for $\% 97.8$ probability between them.

\section{Material and Methods}

Clinicians working in ICUs try to manage successful weaning process so as to decrease the percentage of morbidity and mortality. Thus, they spend much more time for each patient who need no ventilation support. Many researchers have studied about weaning process to decrease clinician's workload in ICUs. The schematic outline of the developed protocol is given in Figure 1. $\mathrm{PH}, \mathrm{PaCO} 2$ and $\mathrm{SpO} 2$ were used to determine acid-base balance and $\mathrm{PaO} 2 / \mathrm{FiO} 2, \mathrm{PEEP}, \mathrm{SaO} 2$ and $\mathrm{Hb}$ were used to determine adequate oxygenation. These two systems were also used to determine final percentage of weaning probability. 


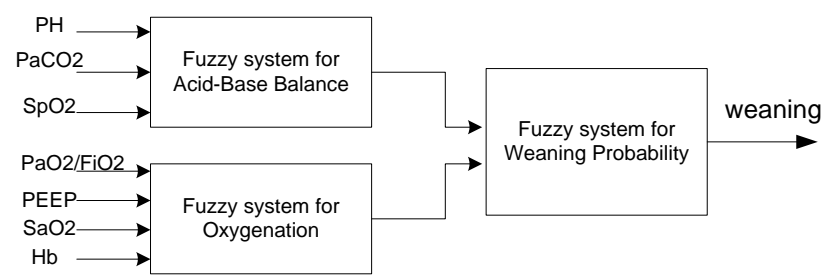

Figure 1. The schematic outline of the developed algorithm

\section{A. Fuzzy System for Acid-Base Balance}

Fuzzy system for acid-base balance has three input such as $\mathrm{PH}, \mathrm{PaCO}_{2}$ and $\mathrm{SpO}_{2}$. The membership functions of fuzzy inputs and output are given Figure 2, 3, 4 and 5.

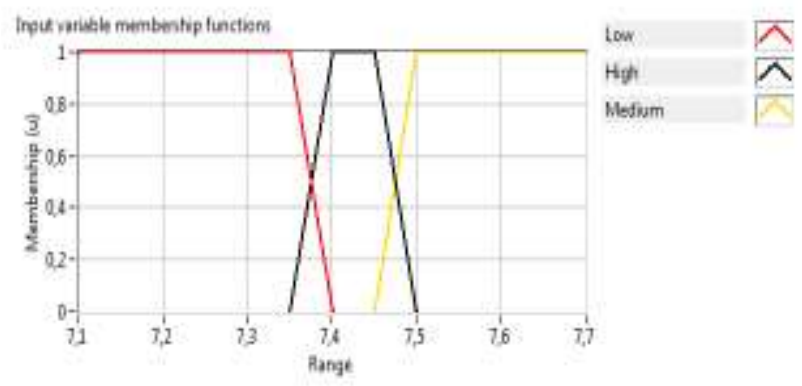

Figure 2. PH membership functions

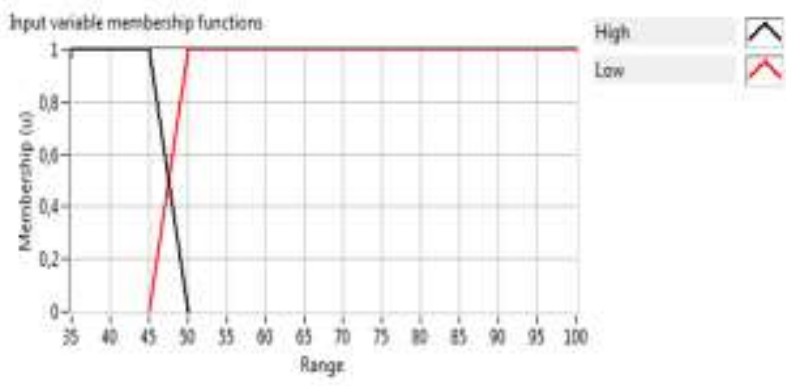

Figure 3. $\mathrm{PaCO}_{2}$ membership functions

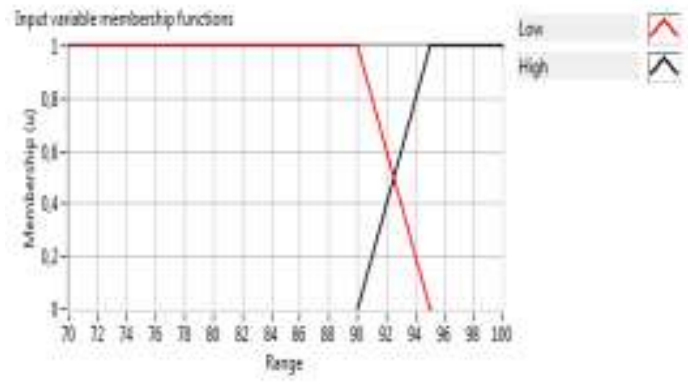

Figure 4. $\mathrm{SpO}_{2}$ membership functions

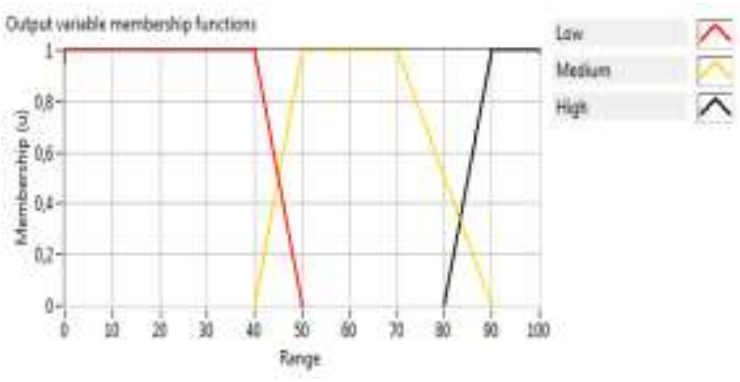

Figure 5. Acid-base balance membership functions

The rule table of the acid-base balance is given in Table 1.

TABLE I. RulE TABLE FOR ACID-BASE BALANCE

\begin{tabular}{|c|c|c|c|}
\hline PH & $\mathbf{P a C O}_{2}$ & $\mathbf{S p O}_{\mathbf{2}}$ & Acid-Base Balance \\
\hline Low & Low & Low & Low \\
\hline Low & Low & High & Low \\
\hline Low & High & Low & Low \\
\hline Low & High & High & High \\
\hline Medium & Low & Low & Low \\
\hline Medium & Low & High & Medium \\
\hline Medium & High & Low & Medium \\
\hline Medium & High & High & High \\
\hline High & Low & Low & Medium \\
\hline High & Low & High & High \\
\hline High & High & Low & High \\
\hline High & High & High & High \\
\hline
\end{tabular}

The all rule table was constituted with clinician's opinion.

\section{в. Fuzzy system for Adequate Oxygenation}

Fuzzy system for adequate oxygenation has four input such as $\mathrm{PaO}_{2} / \mathrm{FiO}_{2}, \mathrm{PEEP}, \mathrm{SaO}_{2}$ and $\mathrm{Hb}$. The membership functions of fuzzy inputs and output are given Figure 6, 7, 8 and 9.

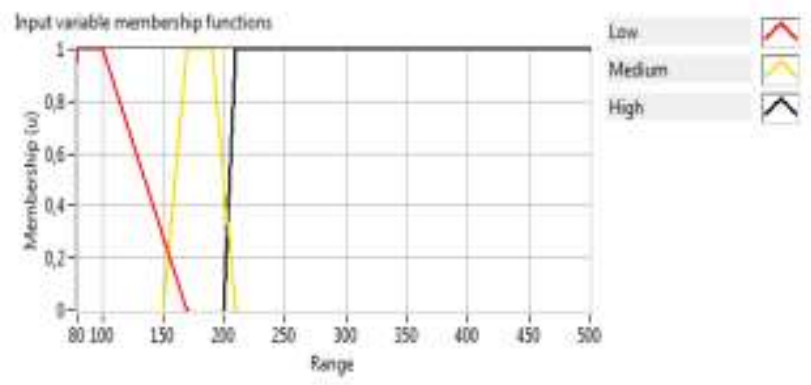

Figure 6. $\mathrm{PaO}_{2} / \mathrm{FiO}_{2}$ membership functions 
Proc. of The Fifth Intl. Conf. On Advances in Computing, Electronics and Electrical Technology - CEET 2016

Copyright (C) Institute of Research Engineers and Doctors, USA .All rights reserved.

ISBN: 978-1-63248-087-3 doi: 10.15224/ 978-1-63248-087-3-20

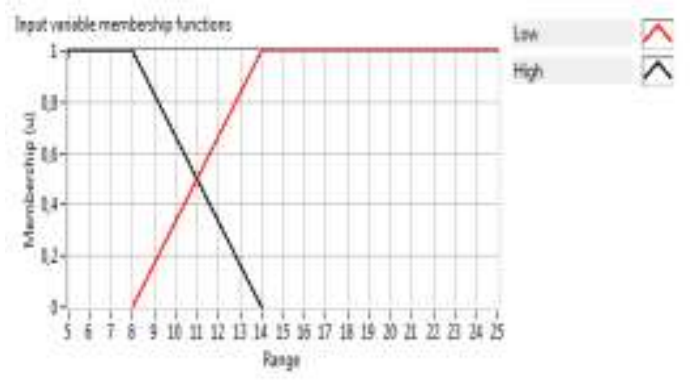

Figure 7. PEEP membership functions

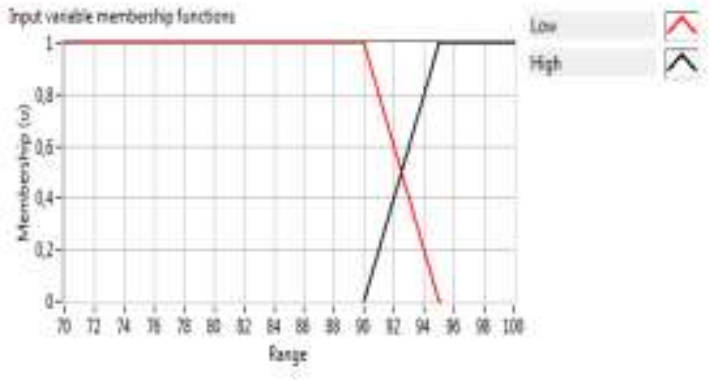

Figure 8. $\mathrm{SaO}_{2}$ membership functions

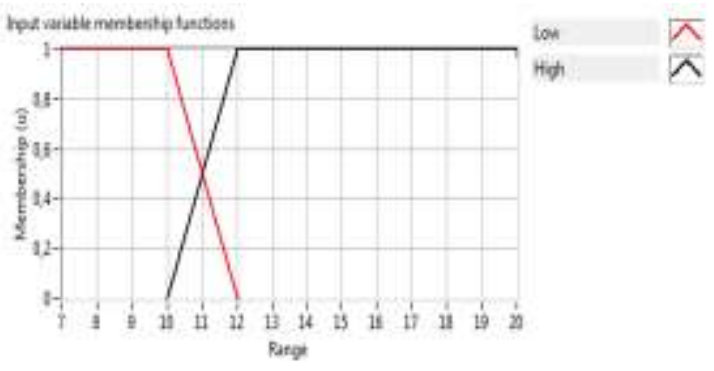

Figure 9. Hb membership functions

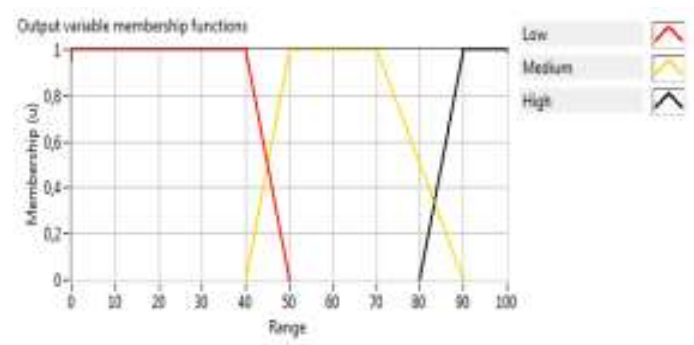

Figure 10. Adequate membership function

The rule table of the acid-base balance is given in Table 2. In this paper, Monte-Carlo simulation and Gaussian distribution method were used to generate random clinical scenarios. Gaussian distribution equation used in this algorithm is given in equation 1,2 and 3.

$$
\begin{aligned}
& f\left(x ; \mu ; \sigma^{2}\right)=\frac{1}{\sigma \sqrt{2 \pi}} * e^{\frac{-(x-\mu)^{2}}{2 \sigma^{2}}} \\
& Z=\frac{\mathrm{x}-\mu}{\sigma}
\end{aligned}
$$

$$
\mathrm{x}=\mathrm{z} \sigma+\mu
$$

Where $\mathrm{x}$ is new data, $\mathrm{z}$ is standard normal distribution, $\mu$ is the mean value, $\sigma 2$ is the variance random value and $\sigma$ is random value.

TABLE II. RULE TABLE FOR ADEQUATE OXYGENATION

\begin{tabular}{|c|c|c|c|c|}
\hline $\mathbf{P a O}_{2} / \mathbf{F i O}_{2}$ & $\mathbf{P E E P}$ & $\mathbf{S a O}_{2}$ & Hb & $\begin{array}{c}\text { Adequate } \\
\text { Oxygenation }\end{array}$ \\
\hline Low & Low & Low & Low & Low \\
\hline Low & Low & Low & High & Low \\
\hline Low & Low & High & Low & Low \\
\hline Low & Low & High & High & Medium \\
\hline Low & High & Low & Low & Low \\
\hline Low & High & Low & High & Medium \\
\hline Low & High & High & Low & Medium \\
\hline Low & High & High & High & High \\
\hline Medium & Low & Low & Low & Low \\
\hline Medium & Low & Low & High & Low \\
\hline Medium & Low & High & Low & Medium \\
\hline Medium & Low & High & High & High \\
\hline Medium & High & Low & Low & Medium \\
\hline Medium & High & Low & High & High \\
\hline Medium & High & High & Low & High \\
\hline Medium & High & High & High & High \\
\hline High & Low & Low & Low & Low \\
\hline High & Low & Low & High & High \\
\hline High & Low & High & Low & Medium \\
\hline High & Low & High & High & High \\
\hline High & High & Low & Low & Medium \\
\hline High & High & Low & High & High \\
\hline High & High & High & Low & High \\
\hline High & High & High & High & High \\
\hline
\end{tabular}

The developed algorithm in LabVIEW is shown in Figure 11 .

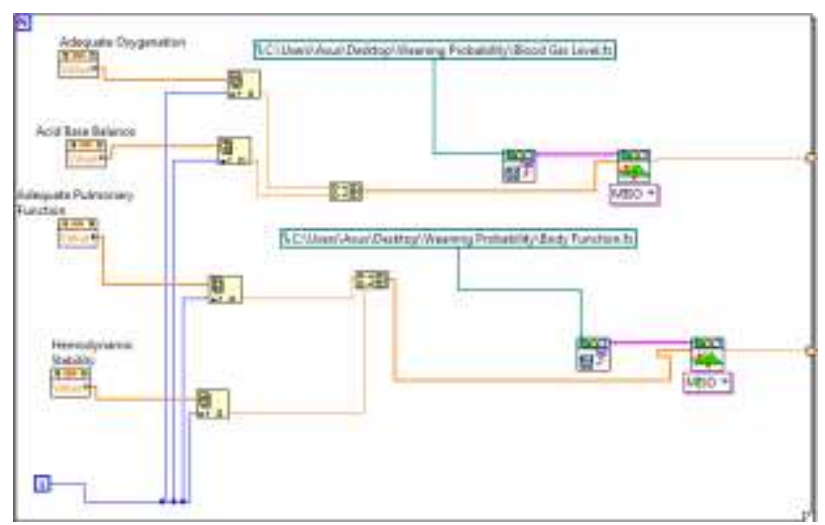

Figure 11. The block diagram of the developed weaning protocol

The output membership function of fuzzy system for weaning probability is given in Figure 12.

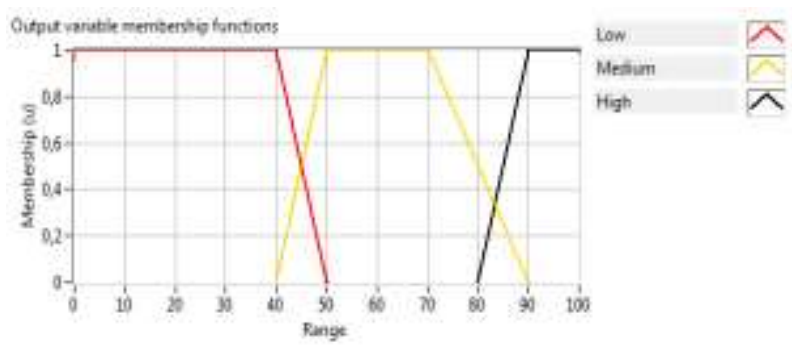

Figure 12 . Weaning probability membership function 
The final rule table of fuzzy system for weaning probability is shown in Table 3.

TABLE III. RULE TABLE FOR WEANING PROBABILITY

\begin{tabular}{|c|c|c|}
\hline $\begin{array}{c}\text { Acid-Base } \\
\text { Balance }\end{array}$ & $\begin{array}{c}\text { Adequate } \\
\text { Oxygenation }\end{array}$ & $\begin{array}{c}\text { Percentage of } \\
\text { Weaning } \\
\text { Probability }\end{array}$ \\
\hline Low & Low & Low \\
\hline Medium & Low & Low \\
\hline High & Low & Medium \\
\hline Low & Medium & Low \\
\hline Medium & Medium & Medium \\
\hline High & Medium & High \\
\hline Low & High & Medium \\
\hline Medium & High & High \\
\hline High & High & High \\
\hline
\end{tabular}

\section{Results}

The developed protocol gives the percentage of weaning probability according to the generated scenarios. In addition, clinician evaluated the each scenario and he gave the percentage of weaning probability. The results obtained from the protocol and clinician's evaluation applied to student t-test for $\mathrm{p}<0.05$. The obtained results are given in Table 4.

TABLE IV. The OBTAINED RESUlts FROM THE DEVELOPED PROTOCOL AND CLINICIAN'S EVALUATION

\begin{tabular}{|c|c|c|}
\hline $\begin{array}{c}\text { Patient } \\
\text { Data (P.D.) }\end{array}$ & $\begin{array}{c}\text { The Percentage } \\
\text { of Weaning } \\
\text { Probability(\%) }\end{array}$ & $\begin{array}{c}\text { The Percentage } \\
\text { of Clinician's } \\
\text { Evaluation(\%) }\end{array}$ \\
\hline 1st P.D. & 78,355257 & $\mathbf{8 0}$ \\
\hline 2nd P.D. & 91,709245 & $\mathbf{9 5}$ \\
\hline 3rd P.D. & 97,858109 & $\mathbf{9 5}$ \\
\hline 4th P.D. & 64,698356 & $\mathbf{6 0}$ \\
\hline 5th P.D. & 92,244709 & $\mathbf{9 0}$ \\
\hline 6th P.D. & 54,745297 & $\mathbf{5 0}$ \\
\hline 7th P.D. & 83,528863 & $\mathbf{9 0}$ \\
\hline 8th P.D. & 93,425975 & $\mathbf{9 0}$ \\
\hline 9th P.D. & 18,753698 & $\mathbf{1 0}$ \\
\hline 10th P.D. & 49,523691 & $\mathbf{5 0}$ \\
\hline 11th P.D. & 22,125896 & $\mathbf{4 0}$ \\
\hline 12th P.D. & 32,458791 & $\mathbf{7 5}$ \\
\hline 13th P.D. & 76,257859 & $\mathbf{6 0}$ \\
\hline 14th P.D. & 62,853257 & $\mathbf{7 0}$ \\
\hline 15th P.D. & 65,525965 & $\mathbf{6 0}$ \\
\hline 16th P.D. & 62,753258 & $\mathbf{9 0}$ \\
\hline 17th P.D. & 84,659874 & $\mathbf{5 0}$ \\
\hline 18th P.D. & 52,326985 & $\mathbf{4 0}$ \\
\hline 19th P.D. & 44,236547 & $\mathbf{6 5}$ \\
\hline 20th P.D. & 65,459632 & \\
\hline & & \\
\hline
\end{tabular}

The Student's t-test was used to determine statistical difference because it assesses whether the means of three groups are statistically different from each other. This test is appropriate whenever a person wants to compare the means of two or more groups [20-23]. Equations 4, 5 and 6 were used to calculate the statistical difference.

$$
\bar{X}=\frac{\sum x}{n}
$$

$$
\begin{aligned}
& s^{2}=\frac{\sum(x-\bar{x})^{2}}{n-1} \\
& t=\frac{\left(\overline{x_{1}}-\overline{x_{2}}\right)}{\sqrt{\frac{s_{1}^{2}}{n_{1}-1}+\frac{s_{2}^{2}}{n_{2}-1}}}
\end{aligned}
$$

Where $x$ is the arithmetic mean, $\mathrm{S}^{2}$ is variance, $\mathrm{t}$ is the test formula, $\mathrm{x}$ is the investigated group and $\mathrm{n}$ is the number of data points in group. According to the results from the ttest, there is no statistical difference for $97.8 \%$ probability between the percentage of developed algorithm results and clinician evaluation.

\section{Discussion}

Weaning patients from mechanical ventilator is important issue. If clinician does not estimate right time for weaning, prolonged ventilation support may cause infection, pneumonia, barotraumas and etc. Thus, many biomedical researchers have tried to create weaning protocol to estimate right weaning time. In literature, there are three basic weaning predictors such as RSBI, PTI and JWI. However, these predictors ignore some patient data so they cannot be universally accepted by clinicians.

In this paper, it was tried to eliminate disadvantages of the predictors used in literature. Seven vital parameters which are easy collected in ICU were used to determine weaning probability. Since the system has seven parameters to estimate weaning probability, some parameters were grouped. Otherwise, the fuzzy system would have 288 rules. However, after grouping, the all systems have 45 rules. $\mathrm{PH}$, $\mathrm{PaCO}_{2}$ and $\mathrm{SpO}_{2}$ were used to determine acid-base balance while $\mathrm{PaO}_{2} / \mathrm{FiO}_{2}, \mathrm{PEEP}, \mathrm{SaO}_{2}$ and $\mathrm{Hb}$ were used to determine adequate oxygenation. Finally, these two systems were used to determine weaning probability. 20 clinical scenarios were generated to test the developed protocol. In addition, clinician evaluated the each scenario and he gave the percentage for it. Each scenario represented a patient in this study. The obtained results from the protocol and clinician's evaluation applied to student t-test for $\mathrm{p}<0.05$ to show statistical difference. The results obtained from t-test, there is no statistical difference for $\% 97.8$ probability between the developed protocol and clinician's evaluation.

\section{Acknowledgment}

This study is part of a project funded by FUBAP grant no. MF.13.21. The authors would like to thank Firat University Hospital-Anesthesia ICU doctors for their invaluable evaluations.

\section{References}

[1] J. H. T. Bates and M. P. Young, "Applying fuzzy logic to medical decision making in the intensive care unit", American Journal of Respiratory and Critical Care Medicine, 167, 948-952, 2003. 
[2] Esteban A., Alia O. and Ibanez J., et al. "Modes of mechanical ventilation and weaning. A national survey of Spanish hospitals". Chest; 106:1188-93. 1994.

[3] Eskandar N. and Apostolakos M.J., "Weaning from mechanical ventilation" Critical care clinics. Apr; 23(2):263-74. 2007.

[4] Neil R. MacIntyre and Chairman M.D., "FCCP evidence-based guidelines for weaning and discontinuing ventilatory support" Chest.;120(6_suppl):375S-396S.

10.1378/chest.120.6_suppl.375S. 2001.

[5] Esteban A., Frutos F. and Tobin M.J., "A comparison of four methods of weaning patients from mechanical ventilation". N Engl J Med 1995; 332:345-50.

[6] Krishnan J.A., Moore D., Robeson C., Rand C.S. and Fessler H.E., "A Prospective, controlled trial of a protocol-based strategy to discontinue mechanical ventilation". Respir Crit Care Med ; 169:673-678, 2004.

[7] Jiin-Chyr Hsu,Yung-Fu Chen,Yi-Chun Du1, Yung-Fa Huang Xiaoyi Jiang and Tainsong Chen, "Design of a clinical decision support for determining ventilator weaning using support vector machine", International Journal of Innovative Computing, Information and Control, Volume 8, Number 1(B), January 2012.

[8] Brochard, L., Rauss, A., Benito, S., Conti, G., Mancebo, J., Rekik,N.,Gasparetto, A. and Lemaire F.,. "Comparison of three methods of gradual withdrawal from ventilatory support during weaning from mechanical ventilation." Am J Respir Crit Care Med.150:896-903. 1994.

[9] Koyuncu A, Yava A., Kurkluoglu M., Guler A. and Demirkilic A., "Weaning from mechanical ventilation and nursing", Turkish Journal of Thoracic and Cardiovascular Surgery doi:10.5606/tgkdc.dergisi..112. 2011.

[10] Guler H., and Ata F. "Development of a fuzzy-based tidal volume algorithm for patients with respiratory distress. Journal of the Faculty of Engineering and Architecture of Gazi University, 29(4), 699-706.

[11] Bien M.Y, Lin Y.S., Shie H.G., Yang Y.L., Shih C.H., Wang J.H. and Cheng K.C., "Rapid Shallow Breathing Index and Its predictive accuracy measured under five different ventilatory strategies in the same patient group"; Chinese Journal of Physiology 53(1): 1-10, 2010, Doi: 10.4077/CJP.2010.AMK013.

[12] Karl L. Yang, M.D. and Martin J. Tobin, M.D., “A prospective study of indexes predicting the outcome of trials of weaning from mechanical ventilation" N Engl J Med 1991; 324:1445-1450.

[13] Bien, M.Y., Hseu, S.S., Yien, H.W., Kuo, B.I.T., Lin, Y.T., Wang, J.H. and Kou, Y.R. "Breathing pattern variability: a weaning predictor in postoperative patients recovering from systemic inflammatory response syndrome". Intensive Care Med. 30: 241-247, 2004.

[14] Vassilakopulos T,Zakynthinos S and Roussos C., "The Tension time index and of respiratory frequency/tidal volüme ratio are the major pathophysiologic determinants weaning failure and success". Am J Respir Care Med 158:378-385.

[15] Bellemare F. and Grasino A., "Effect of pressure and timing of contraction of the human diaphragm fatigue." J Appl Physiol 53: 1190-1195. 1982.

[16] T. Nemoto, G.E. Hatzakis, C.W. Thorpe, R. Olivenstein, S. Dial, J.H.T. Bates, "Automatic Control of Pressure Support Mechanical Ventilation Using Fuzzy Logic" American Journal Respiratory and Critical Care Medicine,Vol.160,no.2,550-556,1999.

[17] Butler R, Keenan SP,Inman KJ, Sibbald WJ and Block G.,. "Is there preferred technique for weaning the difficult to wean patient? A systematic rewiev of the literatüre" Crit Care Med 27: 2331-2336. 1999

[18] Ely E.W. et al., "Effect on the duration of mechanical ventilation of identifying patients capable of breathing spontaneously", $\mathrm{N}$ Eng J Med.;335:1864-9. 1996.

[19] Kilic Y.A., Kilic I., "A novel fuzzy logic inference system for decision support in weaning from mechanical ventilation", Journal of Medical Systems, vol.34,no.6,1089-1095,2010.

[20] Guler H., Turkoglu I., Ata F., "Designing Intelligent Mechanical Ventilator and User Interface Using LabVIEW (R)" Arabian Journal for Science and Engineering, vol.39, no.6, pp. 4805-4813, 2014.
[21] Guler H., Ata F., "Design of a Fuzzy-Labview-Based Mechanical Ventilator" Computer Systems Science and Engineering, vol.29, no.3, pp.219-229, 2014.

[22] Guler H.., Ata F., "The Comparison of Manual and LabVIEWBased Fuzzy Control on Mechanical Ventilation" Proceedings of The Institution of Mechanical Engineers Part H-Journal of Engineering in Medicine, vol.228, no. 9, pp.916-925, 2014

[23] Guzel S., Kaya T., Guler H., "LabVIEW -based analysis of EEG signals in determination of sleep stages" 23th Signal Proces. and Commu. Applications Conf. (SIU), pp. 799-802, 2015.

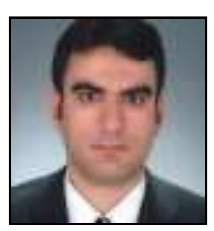

Hasan GULER was born in Elazig, Turkey in 1979. He received the B.S. degree in electrical-electronics engineering from the Firat University, Elazig, Turkey, in 2001, the M.S and Ph.D degrees in electronics engineering in 2007and 2012, respectively. His research areas are biomedical system design, electronics, intelligent control and LabVIEW.

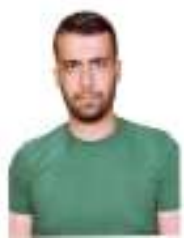

Ugur KILIC was born in Bursa, Turkey in 1988. He received the B.S. degree in electrical-electronics engineering from the Firat University, Elazig, Turkey, in 2013, the M.S. degrees in electronics engineering in 2016. His research areas is biomedical signal processing, LabVIEW..

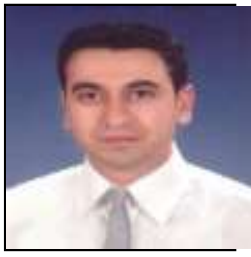

Turgay KAYA was born in Elazig, Turkey in 1982. He received the B.C. degree in electrical-electronics engineering from the Firat University, Elazig, Turkey, in 2003, the M.C. and Ph.D degrees in electronics engineering in 2006 and 2011, respectively. His research areas is biomedical signal processing, optimization and filters. 